\title{
Influence of ionizing radiation on Cobra (Naja haje) and Cerastes cerastes venoms: Toxicological and immunological aspects.
}

\author{
Esmat A. Shaban \\ Assistant Professor, Drug Research Departement, \\ National Center for Radiation Research and Technology, \\ Atomic Energy Authority.
}

\begin{abstract}
The effect of gamma irradiation (15 KGy) on the Cobra Naja haje and Cerastes cerastes venoms toxicity and immunogenicity was evaluated. Irradiated venoms were at least $28.1 \%$ less toxic than non-irradiated venoms. However the antigenic response was not changed as judged by the capacity of irradiated venoms to react with polyvalent antivenom horse serum. The immunodiffusion method showed identity between irradiated and non-irradiated samples.

The effect of gamma radiation on some venom enzymes and venoms profile was studied. Proteolytic, phospholipase $\mathrm{A}_{2}$ and hemorrhagic activities were inhibited by irradiation. Irradiation with gamma rays resulted in structural changes in the venoms as indicated by the changes in their molecular weights.

The results indicated that irradiation of toxic protein -using suitable dose- can promote significant detoxification but still retaining many of the original antigenic and immuonological properties of native venom.
\end{abstract}

\section{Introduction}

Venoms in general are weakly immunogenic, yet fairly toxic (Magalhaes, 1986). This causes problems because serotherapy is the treatment of choice in snake bite-accidents and horse antisera availability is dependent upon venom immunogenicity. To improve antisera production and extend the useful life of immunized horses much effort has been devoted to decrease chronic venom toxicity. Several techniques have been used to detoxify venoms such as mixing the venom with carboxymethlycellulose (Moroz et al.,1963), irradiation by gamma rays (Baride et al ., 1980), adding formaldehyde, (Costa et al., 1985), controlled iodination (Daniel et al., 1987) and encapsulation of purified toxins in liposomes (Freitas and Frezard, 1997).

One method that has been shown to be effective for attenuating venom toxicity and maintaining immunogenicity is gamma radiation (Baride et al., 1980; Hati et al.,1990; Shaban, 1990; Mandal et al., 1993, Nascimento et al., 1996).

Proteins irradiated either in the dry state or in solution undergo chemical and physicochemical changes that can alter their primary , secondary or tertiary structures, while keeping many of their native immunological properties intact (Shalka and Antoni , 1970). Lauhatirananda et al., (1970) observed that several functions of a protein have different radio-sensitivity and that its antigenic properties are the most radioresistant. Hati et al., 1990 showed that Russell viper venom was detoxified by gamma radiation (100 Krad or $200 \mathrm{Krad})$ and used for active immunization of rabbits. Shaban (1990) found that irradiation of Androctonus amorexia scorpion venom with gamma rays in dry state (15 and 30 KGy) decreased its lethal and toxic activity while retaining its antigenicity. Therefore, irradiation of toxic proteins can promote significant detoxification, but still retain many of the original antigenic and immunological properties of native venom.

Snake venoms are complex mixtures which may show qualitative differences in their composition not only between species but also from individual to another $(\mathrm{Tu}, 1977)$. Cerastes cerastes and Naja haje snakes one belong to family Viperidae and 
family Elemedea, respectively. Cerastes cerastes is mainly vasculotoxic in action while Naga hage is mainly neurotoxic.

In this study we describe the effects of a dose of $15 \mathrm{KGy}$ gamma radiation on Cerastas cerastas and Naga hage whole venom to produce detoxified venom with large amount of non-toxic but still immunogenic aggregate with an emphasis on subsequent biological properties and immunogenicity of the irradiated venoms.

\section{Materials and methods:}

\section{Venom:}

Venoms of Naja haje (Egyptian Cobra) and Cerastes cerastes were pooled and obtained from the venom serpentariums, Faculty of Medecine, Ain Shams University . The venoms were obtained by milking healthy snakes, dried and kept in desiccator till used.

\section{Antivenin:}

Egyptian polyvalent antivenin prepared against Naja haje, Cerastes cerastes , Cerastes vipera and Naja nigrocolous obtained as a gift from the Egyptian Organization of Biological products and Vaccines, Agouza, Cairo, Egypt, was used. The lyophilized polyvalent antivenin produced in horses was kept at $4^{\circ} \mathrm{C}$ and reconstituted to $10 \mathrm{ml}$ with distilled water before use.

\section{Irradiation facilities:}

The venoms were irradiated with 15KGy gamma rays in the National Center for Research and Radiation Technology, Cairo, Egypt, using cobalt-60 gamma cell 220, manufactured by the atomic energy of Canada (AECL). The radiation dose rate was 1.4 Rad per second .

In this study, a saline solution of Naja haje and Cerastes cerastes snake venom, were subjected to integral radiation dose level (15KGy). Non-irradiated samples of venoms were used as control.

\section{Animals:}

Male Swiss albino mice weighing between 20-25 gm were used in this study; animals were maintained under standard conditions of food and given standard food add libitum.

\section{Gel chromatography (filtration) techni- que:}

The molecular weights of the irradiated and non-irradiated venoms were determined in the National Research Center, Cairo, Egypt, by the method of Andraws, (1964). $8.0 \mathrm{gm}$ of Sephadex G200 was used for packing the column $(90 \times 1.6 \mathrm{~cm})$ and previously equilibrated with 50 Mtris HCL buffer, pH 7.5. Samples containing $10 \mathrm{mg} / \mathrm{ml}$ of venoms were applied separately to the same column and developed using the same equilibrating buffer at a flow rate of $20 \mathrm{ml} / \mathrm{hr}$; fractions of $6 \mathrm{ml}$ elution volume were collected . Column fractions were monitored for protein at $280 \mathrm{~nm}$.

The column was calibrated by five known molecular weight proteins as standards, cytochrome C $12.4 \quad \mathrm{KDa}$ carbonic anhydrase $29 \mathrm{KDa}$, bovin serum albumn $66 \mathrm{KDa}$, alcohol delydrogenase $150 \mathrm{KDa}$, and B. Amylase $200 \mathrm{KDa}$. Dextran blue (2000000) was used to determine the void volume (V0). A calibration curve was constructed by plotting $\log$ molecular weight versus $\mathrm{Ve} / \mathrm{V} 0$ where $\mathrm{Ve}$ is the elution volume. The molecular weight of each peak was estimated from the standard curve.

\section{Double immunodiffusion technique:}

Immunodiffusion experiments were carried out as described by Ouchterlony (1948). They were carried out using 1.3 Nobel Agar (Difeco. Lab. Detroit, Mich.) in $0.9 \% \mathrm{NaCl}$ solution, sodium azide was added in a concentration of $0.05 \%$, to retard bacterial growth. The wells were filled with $20 \mu 1$ volumes. The venom samples were added in the peripheral wells while the antivenin was added in the central well. After developing of the precipitation bands (48 hr) the plates were washed for $24 \mathrm{hr}$ in saline, dried and stained.

\section{Biological activities of venoms: Lethality assay: \\ Toxicity of venom Naja haje and Cerastes cerastes was established before}




\section{Esmat A. Shaban}

and after 15 KGy gamma irradiation. Lethality was determined by giving the venom intra peritoneally(in different doses) to Swiss albino mice. The LD50 was calculated by the method of Spearman karber (WHO 1981) using six dosage levels. Six mice were used for each dose.

\section{Assay of proteolytic activity:}

Proteolytic activity of non-irradiated and $15 \mathrm{KGy}$ gamma irradiated venoms , was determined with casein (B.D.H.) according to Labib et al. (1980): (EC 3.4 22.17). Mixtures of $1.0 \mathrm{ml}$ of $1 \%$ substrate solution (casein in $0.02 \mathrm{~N} \mathrm{NaOH}, 0.5 \mathrm{ml}$ of 0.1 MTris (hydroxy methyl) aminomethane- $\mathrm{Hcl}$ buffer $(\mathrm{pH} 7.2)$ and $0.5 \mathrm{ml}$ of a dilution of the venom were incubated at $37^{\circ}$ $\mathrm{C}$ for $60 \mathrm{~min}$ followed by shaking with 2.0 $\mathrm{ml}$ of $10 \%$ trichloracetic acid (TCA) solution. After standing for $60 \mathrm{~min}$ the mixtures were clarified by centrifugation or filtered ( using whatmann filter paper) and the absorbance at $280 \mathrm{~nm}$ (A280) of the supernatants or filtrates were determined against zero time tests, which were prepared similarly except that TCA was added before the venom.

\section{Determination of hemorrhagic activity:} Hemorrhagic activity of nonirradiated and 15 KGy gamma irradiated Cerastes cerastes venom was assayed in the skin (intradermally, i.d.) according to Borkow et al. (1993). The minimum hemorrhagic dose (MHD) defined as the amount of venom that produces a hemorrhagic spot of about $1 \mathrm{~cm}$ in diameter after $2 \mathrm{hr}$ ) was determined.

Intradermal observations were carried out after injecting samples of $0.1 \mathrm{ml}$ of nonirradiated and $15 \mathrm{KGy}$ irradiated venom containing 5 MHD into the back skin of six mice. Two hours later the mice were killed and the inner surface of skin was examined.

\section{Determination of phospholipase activity:}

Phospholipase A2 activity of both non-irradiated and 15 KGy gamma irradiated venoms ( Naja haje, Cerastes cerastes), was assayed according to the method of Desnuelle et al.(1955) and Nieuwenhuizen et al. (1974).Lecithin was used as substrate, and was solubilised either with sodium cholate or Triton X-100. The substrate solution was prepared by stirring lecithin at a final concentration of $3.5 \mathrm{mM}$ in $7 \mathrm{mM}$ triton $\mathrm{X}-100,100 \mathrm{mM} \mathrm{NaCl}, 0.055$ $\mathrm{mM}$ phenol red and $10 \mathrm{mM} \mathrm{CaCl} 2$, also $10 \mathrm{mM} \mathrm{NaOH}$ was used as titrant. $1.5 \mathrm{ml}$ of this mixture was introduced into titration cuvette and incubated at $30^{\circ} \mathrm{C}$ for $15 \mathrm{~min}$. $\mathrm{NaOH}$ was added to give absorbance of 1.8 at $558 \mathrm{~nm}$ in a $1 \mathrm{~cm}$ path length cuvette. The reaction was started by adding $20 \mu$ of venom solution at different concentrations and the changes in optical density (O.D.) at 5,10 and $15 \mathrm{~min}$, were recorded. The phospholipase A2 activity was determined as corresponding to the decrease in O.D.

\section{Results}

Gel filtration on Sephadex G -200:

The result of the gel filtration on Sephadex G-200 are presented in (Fig.1). The figure shows that each of the nonirradiated and irradiated crude Naja haje snake venom is separated into three peaks. However, the intensity of the peaks of irradiated samples were lower than the nonirradiated which indicates a breack in the chemical bonds of the irradiated venom molecule. The logarithm of each known molecular weight was ploted against the elution volume (fig.2 standard curve). The molecular weights of all the samples were estimated from the standard curve as shown in (Fig.2).

Also the results indicate that the value of the molecular weights of the nonirradiated Naja haje venom peaks were 14 , 33 and $123 \mathrm{KDa}$ but the molecular weight of the irradiated Naja haje venom tends to progressive shift towards lower molecular weights $(11,21$ and $110 \mathrm{KDa})$ than, the nonirradiated Naja haje venom (Fig. 2).

The result of the non-irradiated and irradiated Cerastes cerastes snake venom results are presented in (Figs. $3 \& 4$ ) . It is clear that the non-irradiated samples had three peaks with molecular weights of 18 , 37 and $110 \mathrm{KDa}$ but the irradiated venom had only two peaks (33 and $110 \mathrm{KDa}$ ) as the smaller molecular weight disappeared. 
The absorption of the irradiated Cerastes cerates venom was lower than the nonirradiated one.

\section{Double immunodiffusion :}

The results of the double immunodiffusion test of non-irradiated and $15 \mathrm{KGy}$ gamma irradiated venoms against a commercial polyvalent Egyptian antivenin , all showed similar patterns; the visible lines obtained in the immunodiffusion reactions were identical and join smoothly at the corners, indicating that there was no change in antigenic determinents (Fig.5 A,B).
Biological activities of venoms:

Lethality assay :

Toxicity assays for the venoms subjected to $15 \mathrm{KGy}$ gamma irradiation are shown in Table 1.

The i.p. LD50 for non-irradiated Naja haje and Cerastes cerastes venom were estimated to be $5 \mu \mathrm{g}$ and $40 \mu \mathrm{g} / 20 \mathrm{gm}$ mouse, respectively. On the other hand, after $15 \mathrm{KGy}$ gamma irradiation of the venom samples, the lethality was affected. Naja haje and Cerastes cerastes were at least $28.1 \%$ and $30.8 \%$ less toxic than the native one.

Table 1: Toxic activity of non- irradiated and $15 \mathrm{KGy}$ irradiated venoms.

\begin{tabular}{|l|c|l|}
\hline Samples & LD50 $(\mu \mathrm{g} / \mathrm{g})$ & $\begin{array}{l}\text { Relative toxicity } \\
\%\end{array}$ \\
\hline Non-irradiated Naga hage venom & 0.251 & $100 \%$ \\
Irradiated Naga hage venom & 0.891 & $28.1 \%$ \\
Non-irradiated Cerastes cerastes venom & 2.00 & $100 \%$ \\
Irradiated Cerastes cerastes venom & 6.50 & $30.8 \%$ \\
\hline
\end{tabular}

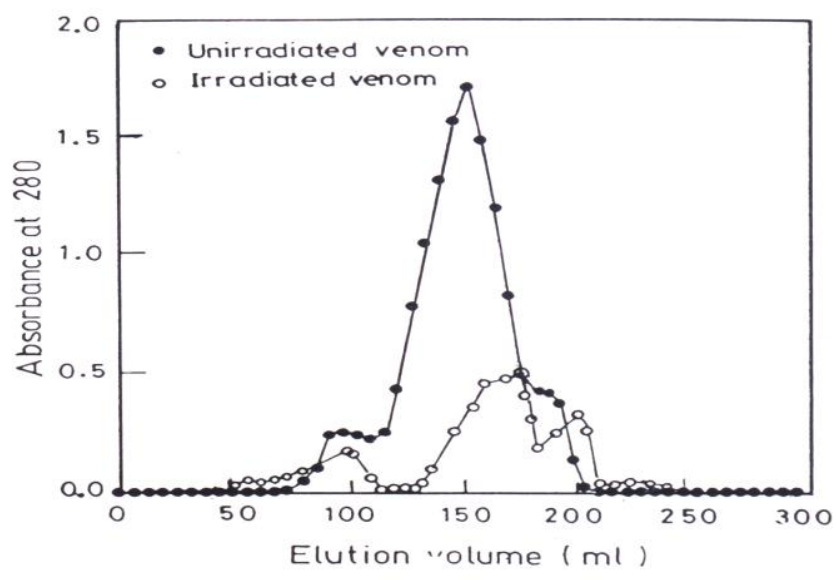

Fig (1): Elution profile of Naja haje snake venom on Sephadex G-200 column 


\section{Esmat A. Shaban}

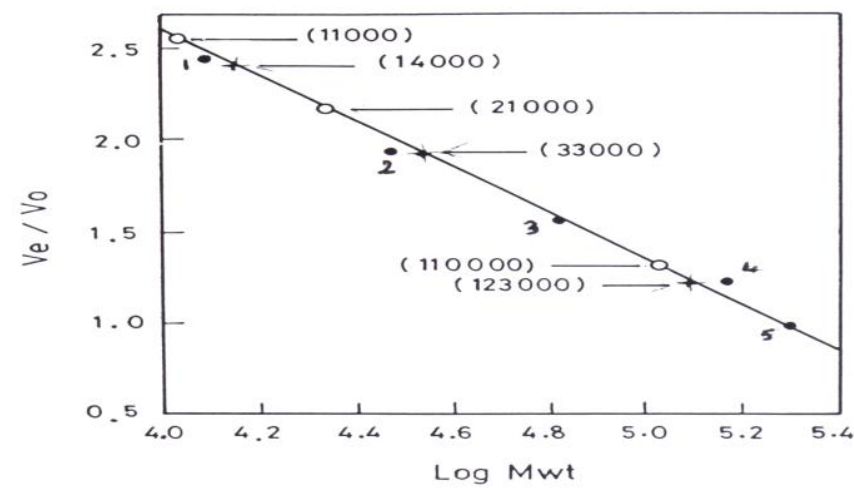

Fig (2): The logarithm of each of known molecular weight (•), irradiated Naje haje venom $(0)$ and the unirradiated venom (+), versus their elution volume.

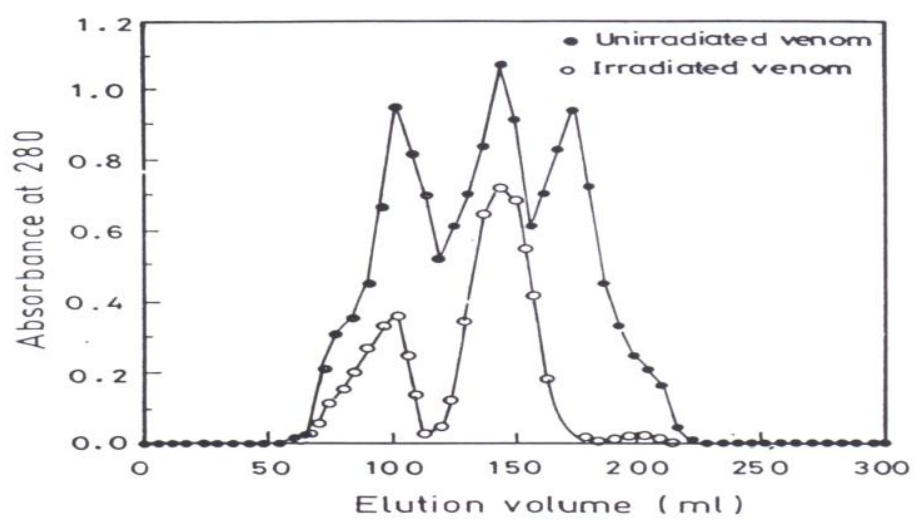

Fig (3): Elution profile of Cerastes cerastes snake venom on Sephadex G-200 column.

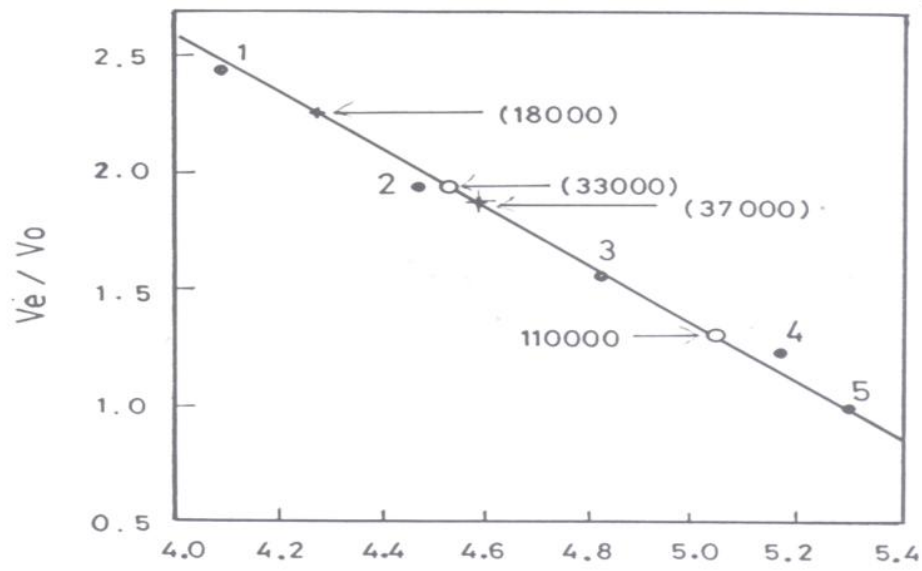

Fig (4): The logarithm of each of known molecular weight (•), and molecular weight of the irradiated (0) and unirradiated (+) Cerastes cerastes snake venom, versus their elution volume. 


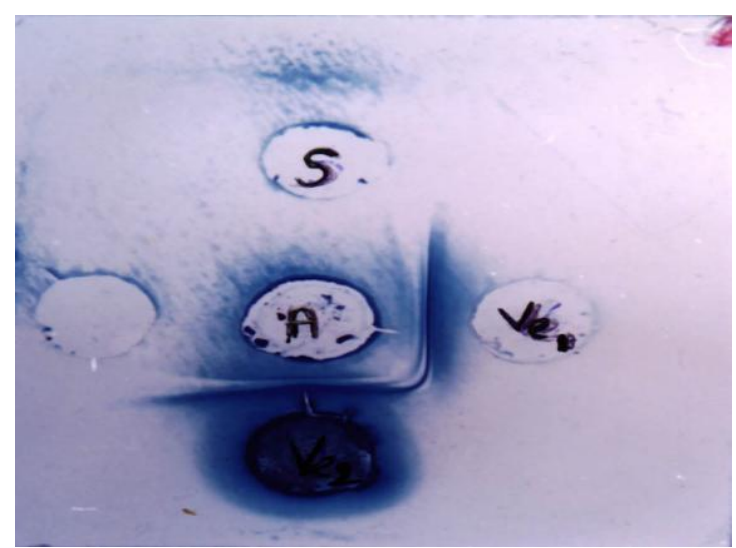

Fig.5 : A- Immunodiffusion reaction of horse serum polyvalent antivenin (in the central well) with non-irradiated and $15 \mathrm{KGy}$ gamma irradiated Naja haje venom $(20 \mathrm{mg} / \mathrm{ml})$.

$\mathrm{S}=$ saline

Ve1= non-irradiated venom

Ve2 $=15 \mathrm{KGy}$ irradiated venom

A=Antivenin

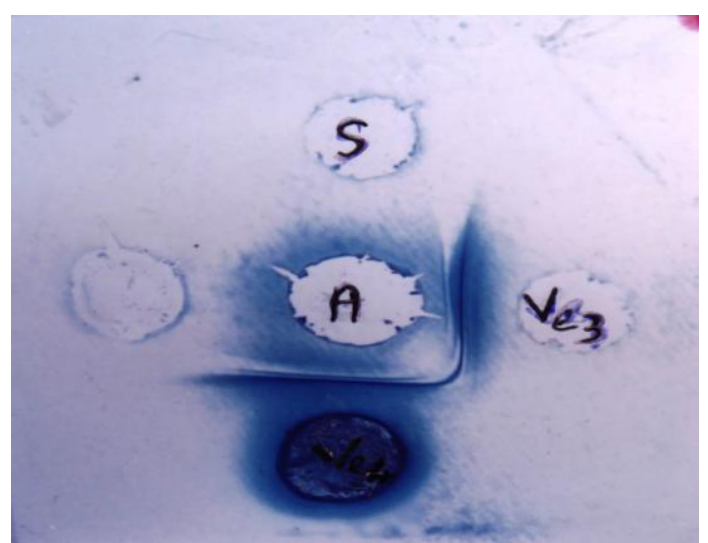

B- immunodiffusion reaction of horse serum polyvalent antivenin (in the central well) with non-irradiated and 15KGy gamma irradiated Cerastes cerastes venom $(20 \mathrm{mg} / \mathrm{ml})$

S- saline

Ve3= non-irradiated venom

Ve4= 15 KGy irradiated venom

A=Antivenin

Hemorrhagic activity:

Table 2 : shows the inhibition of hemorrhagic activity of Cerastes cerastes venom after 15 KGy gamma irradiation.

\begin{tabular}{|l|c|}
\hline Venom & $\begin{array}{l}\text { Hemorrhagic spot area } \\
\mathrm{Cm}^{2}\end{array}$ \\
\hline Non- irradiated Cerastes cerastes venom & $5.5 \pm 0.45$ \\
15 KGy irradiated Cerastes cerastes & $3.8 \pm 0.35$ \\
\hline
\end{tabular}

Non-irradiated and15KGy irradiated whole venom (2.5 $\mu \mathrm{g}: 5 \mathrm{MHD})$ were injected i.d. After $2 \mathrm{hr}$ the mice $(\mathrm{n}=6)$ were killed and the hemorrhagic spots were measured .

Each mean represents the mean of 6 observation $(n=6) \pm$ SE. The difference between non-irradiated and $15 \mathrm{KGy}$ gamma irradiated venom is significant $(\mathrm{P}<0.05)$.

Hemorrhagic activity was strongly inhibited at $15 \mathrm{KGy}$ radiation dose. 


\section{Esmat A. Shaban}

\section{Proteolytic activity :}

Figure 6 A \& 6B represents the inhibition in the proteolytic activity by 15 KGy gamma irradiation of Cerastus cerastes and Naja haje venoms respectively. Phospholipase activity :

Figure 7 and 8 represent the decrease in absorbance at $558 \mathrm{~nm}$ of phenol red as a function of the incubation time with different concentrations of non- irradiated and 15KGy gamma irradiated venoms (Naja haje and Cerastes cerates).

The rapid change of absorbance obtained just after adding the aqueous solution of

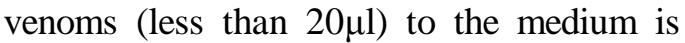
due to phospholipase activity.

It is shown that $15 \mathrm{KGy}$ gamma irradiation inhibits the phopholipase activity of both venom.

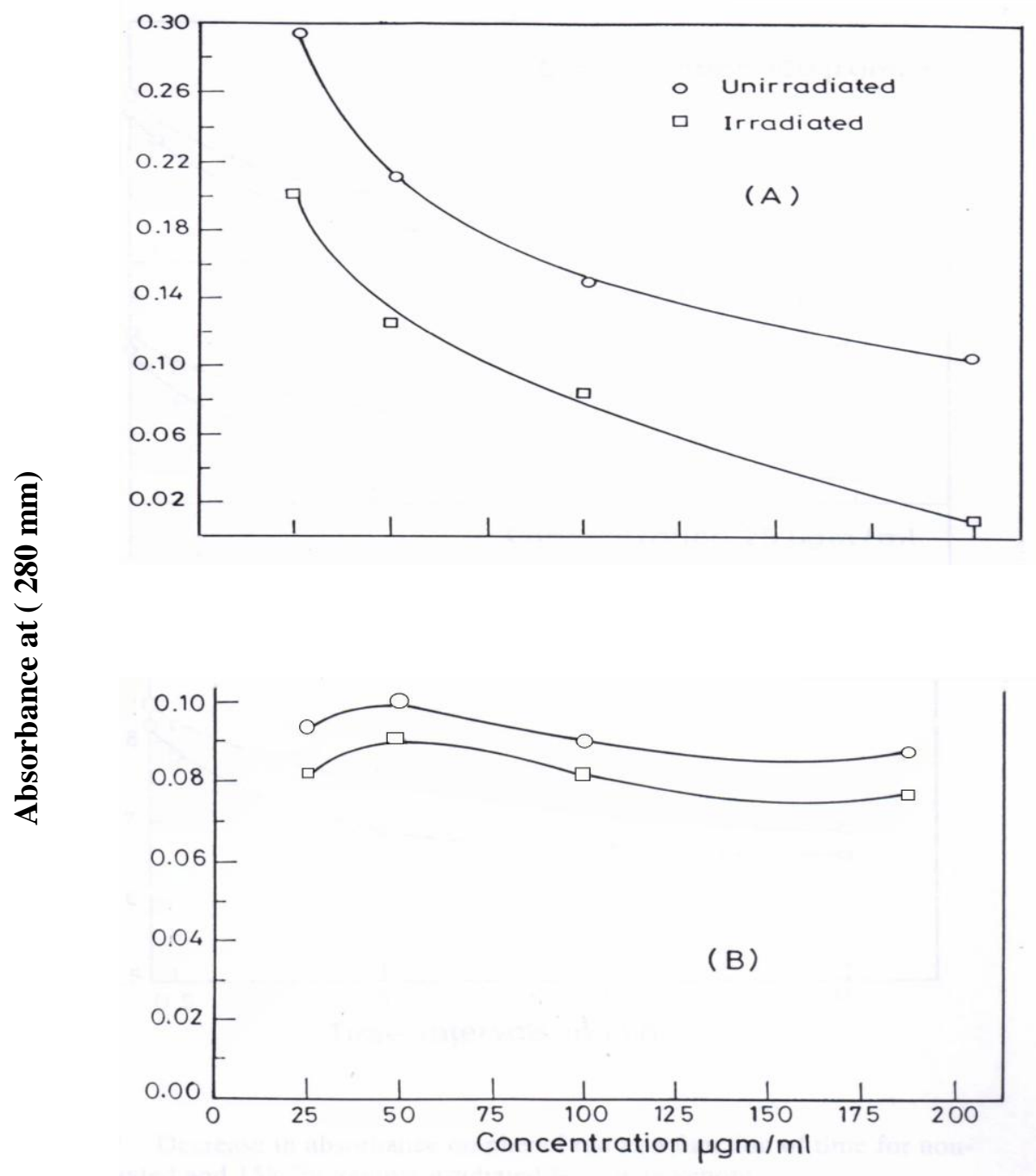

Fig 6 : Effect of 15KGy gamma irradiation on venom protease activity using casein as the substrate.

A- Cerastes cerastes venom

B- Naja haje venom 


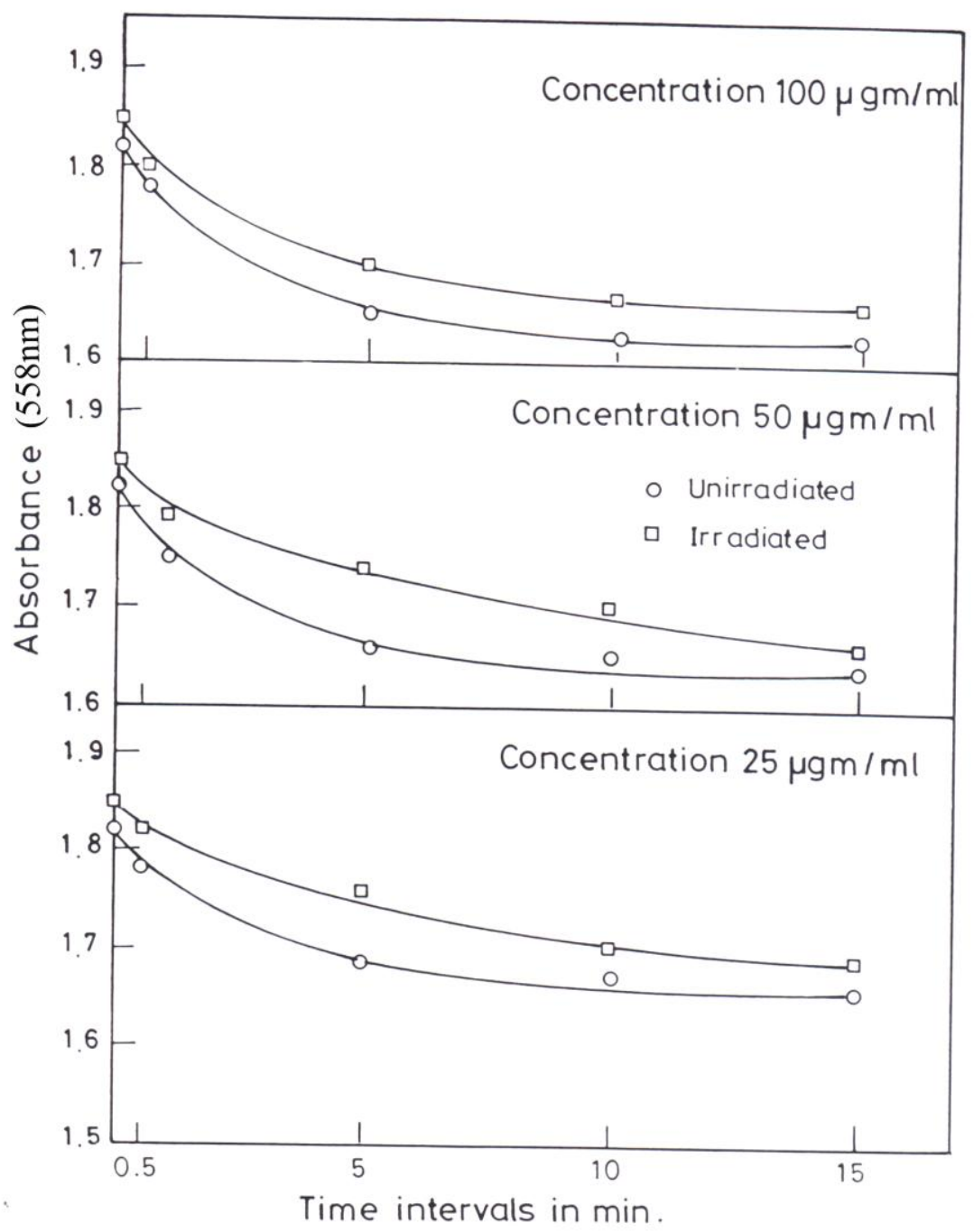

Fig 7 : Decrease in absorbance on phenol red as a function of time for non-irradiated and $15 \mathrm{KGy}$ gamma irradiated Naja haje venom :

The change in absorbance at $558 \mathrm{~nm}$ of medium containing 3,5 $\mathrm{nM}$ lecithin , 4mM cholate, 100nM NaCl , 10nM CaCl2 $0.055 \mathrm{nM}$ phenol red and the different concentrations of Naja haje venom was followed as a function of time at room temperature in a $1 \mathrm{~cm}$ path length cuvette. The phospholipase solution in water was added in a volume smaller than $20 \mu \mathrm{l}$. Recorder tracing represents super imposable data from 4 different solutions. 


\section{Esmat A. Shaban}

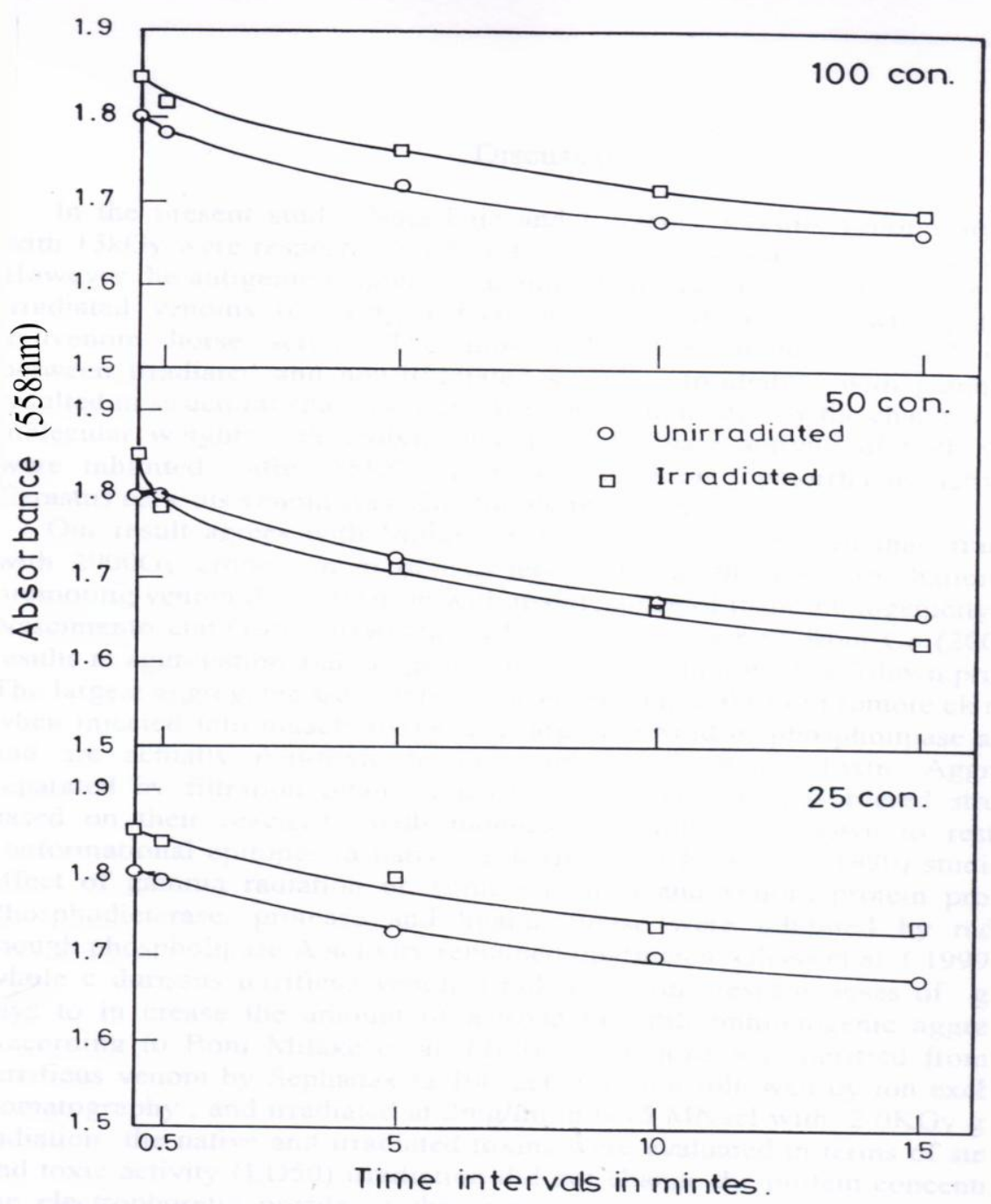

Fig 8 : Decrease in absorbance on phenol red as a function of time for non-irradiated and 15KGy gamma irradiated Cerastes cerastes venom :

The change in absorbance at $558 \mathrm{~nm}$ of medium containing 3,5 $\mathrm{nM}$ lecithin , 4mM cholate, 100nM $\mathrm{NaCl}, 10 \mathrm{nM} \mathrm{CaCl} 2 \mathrm{0.nM}$ phenol red and the different concentrations of Cerastes cerastes venom was followed as a function of time at room temperature in a $1 \mathrm{~cm}$ path length cuvette. The phospholipase solution in water was added in a volume smaller than $20 \mu$ l. Recorder tracing represents super imposable data from 4 different solutions. 


\section{Discussion}

In the present study,the $15 \mathrm{KGy}$ irradiated Naja haje and Cerastus cerastus venoms were $28.1 \%$ and $30.8 \%$ less toxic respectively than the native ones.

However, the antigenic response was not changed as judged by the capacity of irradiated venoms to react with a polyvalent antivenom horse serum. The immunodiffusion method showed identity between irradiated and non-irradiated samples. Irradiation with gamma rays resulted in structural changes in the venoms as indicated by the changes in their molecular weights. Proteolytic and phospholipase activity of both venoms were inhibited after $15 \mathrm{KGy}$ gamma irradiatio-n, and the hemorrhagic activity of Cerastus cerastus venom was also highly inhibited.

Our result agrees with Murata et al. (1991) who showed that irradiation with 2000Gy crude venom of c.d. terrificus was the ideal irradiation dose, promoting venom detoxification with maintenance of its immunogenicity. After Nascimento et al. (1996) irradiation of crotoxin by X-rays from Co (2000 Gy) results in aggregation and the generation of lower mol.wt. breakdown products. The largest aggregates are greatly reduced in their ability to promote creatine kinase (ck) release when injected into muscle tissue, are largely devoid of phospholipase activity and are actually non-toxic to mice relative to the native toxin. Aggregates separated by filtration retain at least part of their higherordered structure, based on their reactivity with monoclonal antibodies known to rest with conformational epitopes in native crotoxin. Also Hati et al .(1990) studied the effect of gamma radiation on some enzymes and venom protein profiles. Phosphodieterase, protease and hyaluronidase were inhibited by radiation though phospholipase A activity remained unaffected. Glissa et al. (1999) used whole C. durissus terrificus venom irradiated with increscent doses of gamma rays to increase the amount of a toxic but still immunogenic aggregate . According to Boni Mitake et al, (2001) crotamine was purified from C. d. terrificus venom by Sephadax G-100 gel filtration followed by ion exchanger Somatography, and irradiated at $2 \mathrm{mg} / \mathrm{ml}$ in $0.15 \mathrm{MNaCl}$ with $2.0 \mathrm{KGy}$ gamma radiation, the native and irradiated toxins were evaluated as regards structure and toxic activity (LD50). Irradiation did not change the protein concentration, the electrophoretic profile or the primary structure of the protein although differences were shown by spectroscopic techniques. Gamma radiation reduced crotamine toxicity by $48.3 \%$ but did not eliminate it.

Snake venoms are complex mixtures of toxins and enzymes, and there pharmacologic effects result from both the direct effect of the toxin and the indirect effects of enzymes, such as by liberation of autopharmacologic substances such as bradykinin and histamine (Lee, 1979 ).

Cobra toxin was shown to consist of a single peptide chain cross linked intramolecularly by four disulfide bonds that were essential for toxicity (Yang 1970).

It is known that most proteolytic and hemorrhagic components so far isolated from snake venoms are proteins with relatively high molecular weights ( usually more than 20000). Also snake venom phospholipases mol.wt. are high (range from 8500 to 36000) ( $\mathrm{Tu}, 1977 \& 1982)$. That is why snake venoms are highly affected by radiation which inhibits their toxic activity.

It was well known that the doses of the order of Kilograys used in detoxification of the venom influenced both the physio-chemical properties and the biological activity of macromolecules, when irradiated in aqueous media or even in the solid state (Antoni,1973; Hayes, 2001) since there is a close interrelationship between the structure and the biological activity of macromolecules, some alteration appeared to be the most possible explanation for the radiation effects.

As regards the effect of radiation on proteins, the amino group is the most radiosensitive portion of an amino acid. However, in the formation of a protein, this groupes linked to a carboxyl group and it is, therefore, not easily removed from the molecule. Similarly, the carboxyl group is 


\section{Esmat A. Shaban}

no larger available for the reaction. Thus, the side-chains are the most radiosensitive portion of a protein molecule. The specific changes which occur in the side-chains depend on their chemical composition. A hydrogen atom may be removed or a break may occur between, almost, many of the atoms in the chain (Cassarett,1968).

Loss of function of protein by irradiation, is not usually due to breaking peptide bonds, or otherwise, disrupting the primary skeletal structure of the peptide chain. It may result from a change in a critical side chain or from a break in the hydrogen or disulfide bonds which in turn, can result in a disorganization of the internal relationships of side chain groups, or an exposure of amino-acid groups, resulting in a change in bilogical activity (Hayes, 2001).

Souza -Fillo et al. (1992) found that crotoxin, the major neurotoxin of the South American rattlesnake was irradiated with a Co- 60 gamma source at doses of 250, 500, 1000,1500 and $2000 \mathrm{~Gy}$. Irradiated crotoxin was analysed for free SH-groups, protein concentration, electrophoretic profile, $50 \%$ lethal dose (LD50) in mice, and antigenicity against crotalic antiserum by diffusion immuno -assay. The dose of 1000Gy cleaved 0.95disulfide bridges / $\mathrm{mol}$ and 1500Gy cleaved 1.42 bridges/ mol, indicating the importance of disulfide bond integrity for inducing toxicity.

It seems most probable that, the radiation, has affected the three dimensional configuration of the molecule, causing it to unfold and make the disulfide bond available for reactions. Since the venom was irradiated in solution state, the changes have been attributed largely to indirect action of the radiation on the protein molecules. Such an indirect action in an aqueous system is mainly through shortlived radicals such as $\mathrm{OH}, \mathrm{H}, \mathrm{HO} 2$ and free electrons and molecular systems such as H2O2 and O2 (Alvin and Edvin, 1964).

Thus, our results suggest that the treatment with gamma radiation is a suitable way to detoxify Naja haje as well as Cerastus cerastus venom without affecting their immunogenicy provided that a proper dose is used and, therefore, proper toxoid could be obtained.

\section{References}

1. Alvin,G. and Edvin,J.H. (1964): in: Basic mechanisms in the radiation chemistry of aqueous media, Proc. Conf. Nat. Acad. Sc; Nat. Res. Council of United Stated, Gathinburg, Tenn., Radiat. Res. Suppl. L, Academic press.

2. Andraws, B.(1964): Estimation of the molecular weight of protein by Sephadex gel filtration . Biochem. J. 91, 222-223.

3. Antoni, F., (1973): The effect of ionizing radiation on some molecules of biological importance. In: Manual on Radiation Sterilization of Medical and Biological Materials. Tech. Rep. Series, No 149, PP.13-21.

4. Baride, M., Jain, S.D. and Gaitonde, B.B., (1980): Biochemical studies on toxoids of venoms of poisonous Indian snakes. Indian. J. Med. Res. 72, 571-576.

5. Boni-Mitake, M., Costa, H., Spencer, P., Vassilieff, V.S.and Rogero, J.R. (2001): Effect of Co-gamma radiation on crotamine. Braz. J. Med. Biol. Res 34 (12)1531-1538

6. Borkow, G., Gutierrez, J.M. and Ovadra, M.(1993): Isolation and characterzation of synergistic hemorrhaging from the venom of the snake .Bothraps asper. Toxicon 31, 1137-1150.

7. Cassarett,A.P. (1968): Radiation biology. Published by Englewood Cliffs, prentice Hall Inc., New Jersey, PP, 74-80.

8. Costa, L.M., Takeda, A.K., Barbosa, S.F.C., Berra, J.A.P., Adelino, M.G.F., Soerensen, B., Pinto. J.R.and Vancetto, M.D.C., (1985): Estudo comparativo da reposta immune de cavalos do veneno de Crotalus durissus terrificus, in natura, tratado com formaldeidoe submetido a açao termica. Vac. Soros 1, 24-29.

9. Daniel. J.P., Heneine.L. G. D., Tavares, C.A.P. Nascimento, M.C.S.and Heneine,I.F., (1987): Generation of protective immune sera by Crotalus durissus trrificus venom detoxified by controlled iodination. Braz.J. Med. Biol. Res. 20. 713-720.

10. Desnuelle, P., constantin, M.J. and Baldy, J. (1995) : Technique potentiometrique pour la mesure de l'activité de la lipase pancréatique. Bull. Soc. Chim. Biol. 37,285 . 
11. Do-Nascimento,N, Seebart, C.S., Francis, B; Rogero, J.R and Kaiser, I,I. (1996). Influence of ionizing radiation on crotoxin : biochemistry and immunilogical aspects. Toxicon 34 : 123-131.

12. Freitas, T.V. and Frezard.F.,(1997): Encapsulation of native crotoxin in liposomes: a save approach for the production of antivenom and vaccination against crotalus durissus terrficuus venom. Toxicon 35, 91-100.

13. Glissa, P.B., Nascimento, N. and Rogero,J.R., (1999): Toxicity and immunogenecity of Crotalus durissus terrificus venom treated with different doses of gamma rays. Toxicon .37, 1131-1141.

14. Hati.R.N. Mandal .M .and Hati .A. K., (1990): Active immunization of rabbit with gamma irradiated Russel's viper venom toxoid. Toxicon 28.895-902.

15. Hayes,A. and Francis (2001): Principles and methods of toxicology fourth edition ( $4^{\text {th }}$. Ed.) edited by A. Wallace Hayes, Taylor and francis, P 715.

16. Labib, R.S., Awad, E.R.and Farag, N.W. (1980): Proteases of Cerastes cerastes (Egyptian Sand Viper) and Cerastes Viper (Sahara sand Viper) snake venoms. Toxicon. 19.73-83.

17. Lauhatirananda, P., Ganthavorn, S. and Hagodom, V., (1970): Radiation effect on Cobra venom. International Atomic Energy Agency- PL- 334/10, 107-112.

18. Lee,C.Y.(1979): Snake venoms. Handbook of experimental pharmacology, vol. 52. Springer-Verlag, Berlin.

19. Magalhaes, R.A., Ribeiro. M.M.F., Rezende N.A. and Amaral., C.F.S. (1986): Rabbomiolise secundaria a acidente crotalico (Crotalus durissus terrficus). Rec. Instmed. Trop, Sao Paulo 28,228-233.

20. Mandal, M., Hati, R.N and Hati, A.K., (1993): Neutralization of pathopysiological manifestations of Russel viper envenoming by antivenom raised against gamma irradiated toxoid. Toxicon 31, 213-216.

21. Moroz. C., Goldblum. N.and Vries, A. (1963) : Preparations of vipera palestinae antineurotoxin using carboxy methyl cellulose bound neurotoxin as antigen. Nature, 200. 697-698.

22. Nieuwenhuizen, W., Kunze, H. and De Haas, G.H. (1974): phospholipase A2 (phosphotide acylhydrolase. E.C 3.1.14) from porcine pancreas. In: Methods in Enzymology, Vol.32 PP.147 (Flesher, S.and Packer, I.,m Eds) New York Academic press.

23. Ouchterlony,O. (1948): In vitro method for testing the toxin production capacity of diphtheria bacteria Acta Path. Microbiol.Scand., 25:186.

24. Shaban, E.A., (1990): Ph. D. Thesis, Faculty of Pharmacy, Alexandria University.

25. Skalka. M.and Antoni. F. (1970): Effect of radiation on the biological properties of proteins. In: Radiation sensitivity of toxins and animal poisons. 1969. Bangkok. Proceedings of a panel, Bangkok. 19-22

26. Souza-Fillo J.N., Guarien-Cruz M.C., Murata Y. and Rogero J.R. (1992): Detoxification of the crotoxin complex by gamma radiation Braz. J. Med.Biol. Res. 25 (2): 103-113.

27. Tu, A. T. (1977) : proteolytic enzymes. In: Venoms Chemistry and Molecular Biology. P.104. New York: John wiley and Sons.

28. Tu, A.T. (1982): Chemistry of rattlesnake venoms In: Rattlesnake venoms, their actions and treatment. P. 247 (tu, A.T., Ed.) New York: Marcel Dekker.

29. World Health Organization (WHO) (1981): Progress in the Characterization of venom and standardization of antivenoms. W.H.O. off set publication. Geneva, Switzerland, 58, 7-42.

30. Yang, C.C. (1970) : Structure activity relatioship and immunochemical studies on corotoxin in: Radiation sensitivity of toxins and animal poisons. Proceeding of a panal on the radiation sensitivity of toxins and animal poisons organized by the IAEA and held in Bankok. PP.63-74 


\section{تأثير الأشعة المؤينة علي الخواص السمية و المناعية لسم الكوبرا

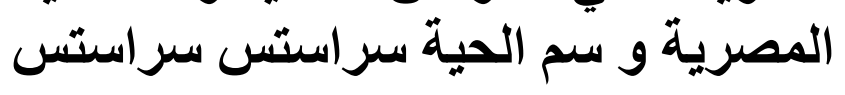

د. عصمت عبد السلام شعبان

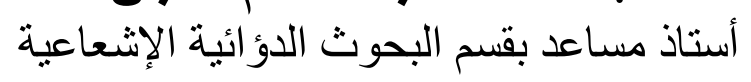

المركز القومي لبحوث و تكنولوجيا الإشعاع/ هيئة الطاقة الذرية الذية

تم في هذا العمل دراسة تأثير أشعة جاما بجر عة 15 كيلو جر اي علي كل من السمية

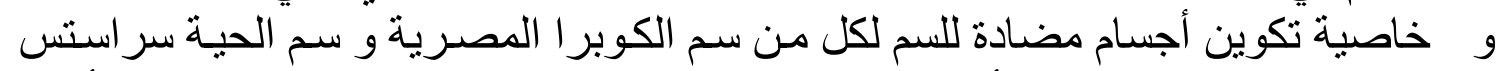

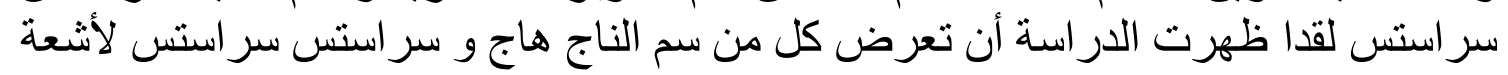

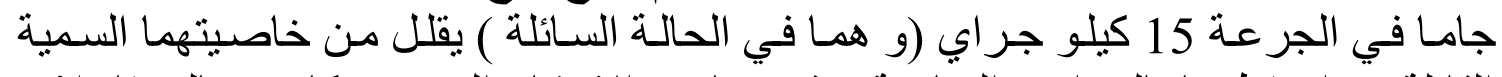

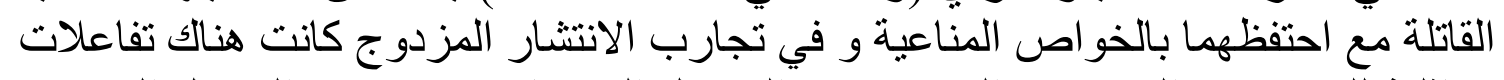

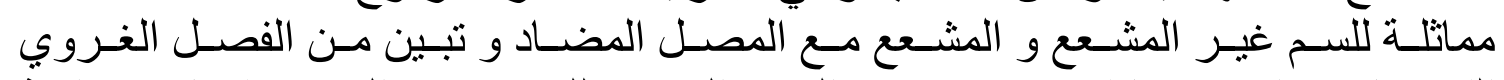

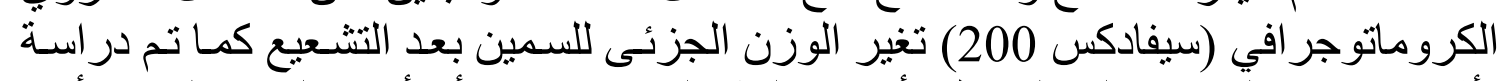

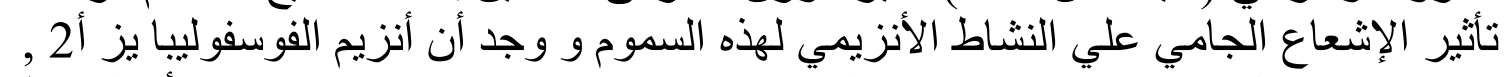

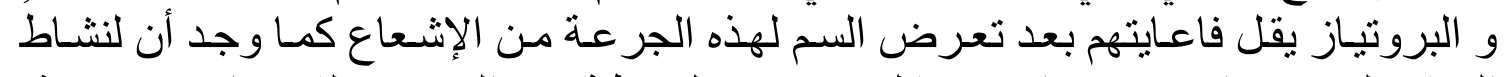

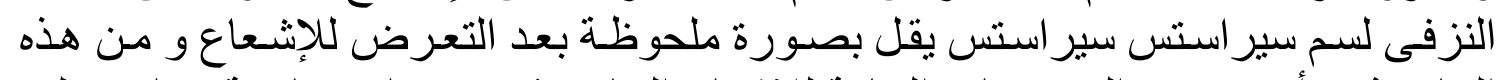

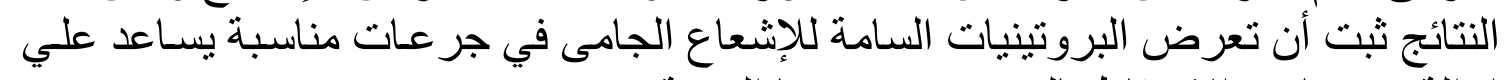
إز الة سميتها مع الاحتفاظ بالعديد من خوصها السمينة. 